\title{
TRABALHO DOCENTE E EMANCIPAÇÃO FEMININA NO OESTE PAULISTA NOS ANOS DOURADOS
}

Jorge Luís Mazzeo Mariano

Universidade do Oeste Paulista - UNOESTE, Programa de Pós-Graduação em Educação, Presidente Prudente, São Paulo. E-mail: jorgemariano86@yahoo.com.br. Agência de fomento: CAPES

\section{RESUMO}

O presente texto discute os avanços alcançados pelas mulheres brasileiras em meados do século $X X$, especialmente no que tange à possibilidade de se educarem. $O$ objetivo deste estudo foi exibir de modo panorâmico os avanços e os retrocessos enfrentados pelas mulheres, especialmente as professoras da região oeste do Estado de São Paulo, nos chamados anos dourados (década de 1950). Em relação à metodologia adotada, primeiramente foi realizado um levantamento em fontes bibliográficas; posteriormente, foram realizadas entrevistas semiestruturadas com os indivíduos do contexto histórico considerado para a pesquisa. Foi por meio da mesma educação que as mulheres puderam vislumbrar uma vida diferente em relação àquela vivida pelas suas antepassadas. Assim, foi possível perceber uma ampliação das perspectivas profissionais para as mulheres nos anos dourados, uma conquista alcançada principalmente pelo aumento de sua escolaridade.

Palavras-Chave: Trabalho docente, educação, emancipação feminina, oeste paulista, anos dourados.

\section{TEACHING WORK AND FEMALE EMANCIPATION IN WEST PAULISTA IN THE GOLDEN YEARS}

\begin{abstract}
This paper discusses the advances made by Brazilian women in the middle of the 20th century, especially regarding the possibility of educating themselves. The aim of this study was to show in a panoramic way the advances and setbacks faced by women, especially the teachers of the western region of the State of São Paulo, in the so-called golden years (1950s). In relation to the adopted methodology, a survey was first carried out in bibliographical sources; Subsequently, semistructured interviews were conducted with individuals from the historical context considered for the research. It was through the same education that women could glimpse a different life compared to that lived by their ancestors. Thus, it was possible to perceive an expansion of the professional perspectives for the women in the golden years, a conquest reached mainly by the increase of their schooling.
\end{abstract}

Keywords: Teaching work, education, feminine emancipation, west paulista, golden years. 


\section{INTRODUÇÃO}

Este trabalho é um recorte da tese de doutorado em Educação intitulada As influências do trabalho docente feminino na cultura escolar do extremo oeste paulista (1932-1960), desenvolvida no âmbito do Programa de Pós-Graduação em Educação da Universidade Estadual Paulista Unesp (Campus de Presidente Prudente), e defendida em 2016.

O presente texto discute os avanços alcançados pelas mulheres brasileiras em meados do século $X X$, especialmente no que tange à possibilidade de se educarem, e exibe como a moralidade vigente ainda representaria um importante entrave à igualdade de oportunidades entre os gêneros ${ }^{1}$.

Assim, o principal objetivo deste estudo foi exibir de modo panorâmico os avanços e os retrocessos enfrentados pelas mulheres, especialmente as professoras da região oeste do Estado de São Paulo, nos chamados anos dourados (década de 1950).

\section{METODOLOGIA}

Em relação à metodologia adotada, primeiramente foi realizado um levantamento em fontes bibliográficas, de obras relativas à condição social da mulher durante o Nacional Desenvolvimentismo; à feminização do magistério; ao contexto político e educacional de 1950. Feito esse levantamento, o passo seguinte compreendeu o estudo e a catalogação dessas obras através de fichamentos, delimitando assim o objeto de pesquisa. Em seguida, foi traçado um panorama do contexto no qual o gênero feminino, especialmente as professoras, da região estavam inseridas.

Posteriormente, foram realizadas entrevistas semiestruturadas com os indivíduos (professoras e educandas/os) que fizeram parte, direta ou indiretamente, do contexto histórico considerado para a pesquisa ${ }^{2}$. Através das narrativas, valiosas informações que muitas vezes não constam nos documentos, relatórios, livros ou jornais, podem ser obtidas contribuindo para a compreensão de processos de constituição dos sujeitos. (ALBERTI, 2005; FERREIRA \& AMADO, 2006; JOUTARD, 1986; THOMPSON, 1992).

Neste sentido, as fontes bibliográficas se juntaram aos relatos orais no presente estudo. Thompson (1992) indica que existem três modos pelos quais a História Oral se constitui: pela utilização dos relatos da vida de um só sujeito; através da coletânea de histórias de vida; e pela análise cruzada, na qual os relatos orais são utilizados como fontes de informação e são agregados a outros tipos de fontes. Portanto, foi aplicada a análise cruzada nesta pesquisa.

\section{RESULTADOS}

Apesar das várias amarras morais que impediam a projeção feminina no espaço público da sociedade ao longo de toda a História do Brasil, o século XX representou um tempo de relevantes progressos para as mulheres.

Foi por meio da mesma educação que as mulheres puderam vislumbrar uma vida diferente em relação àquela vivida pelas suas antepassadas. Se no princípio a escolarização visava ajustar as mulheres aos moldes tradicionais, para que melhor cumprissem com a sua "sagrada missão" no lar, posteriormente elas foram requisitadas a exercer a função docente, assumindo-a e sobrepujando numericamente os homens nessa carreira. Com essa senda aberta, as mulheres puderam fazer da educação o trampolim para o espaço público, alcançando outras vias que Ihes possibilitaram a atuação na política, na ciência e na economia.

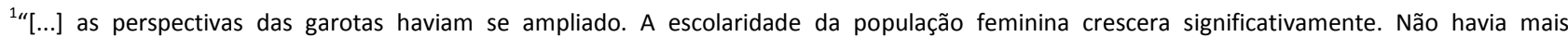
questionamentos escancarados sobre o direito das mulheres de receber educação formal (com exceção de ressalvas à formação universitária) e já existiam instituições capazes de oferecê-la. Embora ainda houvesse tópicos curriculares diferenciados para moças e grandes dificuldades de ingressar em cursos ou profissões consideradas 'masculinos', um avanço notável ocorrera". (PINSKY, 2011, p. 481).

${ }^{2}$ A pesquisa foi cadastrada no Comitê de Ética em Pesquisa da FCT/Unesp e na Plataforma Brasil (número do parecer: 270.609. Protocolo de aprovação CAAE: 12952613.8.0000.5402).
} 


\section{DISCUSSÃO}

A partir da década de 1950 a imagem da mulher - apesar de preservar alguns elementos das décadas anteriores - mudou bastante. A ampliação do número de cidades e o aumento das já existentes forneciam novas formas de atuação às mulheres, algo que causava certa desconfiança nos indivíduos acostumados a anos de servidão de suas esposas e filhas. Mas seria difícil esquecer os vários anos utilizados para construir a moral e o padrão comportamental especialmente destinado às mulheres ${ }^{3}$.

A aceitação da mulher no mercado de trabalho se dava com várias reservas, especialmente no que se refere à questão salarial. No tocante ao assunto do trabalho feminino remunerado era possível perceber que as mulheres ainda continuavam submetidas aos mesmos padrões androcêntricos das décadas anteriores.

[...] Além da incapacidade econômica do país em absorver a totalidade da força de trabalho feminina disponível, os preconceitos machistas e as obrigações domésticas impediram muitas mulheres, mesmo educadas e bem preparadas, de ingressar no mercado de trabalho. Quando o ingresso ocorria, concentrava-se em determinadas profissões consideradas "adequadas às mulheres", nos serviços de escritório, na indústria de vestuário, nas atividades ligadas ao Ensino e à Saúde. (PINSKY, 2011, p. 506).

Embora a escolaridade das mulheres tivesse se ampliado, ainda existiam mecanismos que não permitiam que esta fosse completa. Numericamente mulheres e homens quase se equiparavam no ensino secundário. Estudos recentes (SOUZA; DINIZ, 2014) demonstram que no Estado de São Paulo essa proporção chegou a se desiquilibrar, tendo se verificado, em alguns casos, uma maior incidência feminina no ensino secundário. Isto se dava em função da grande ampliação dos ginásios no Estado de São Paulo, entre 1930 e 1960, o que proporcionou as condições para que as meninas pudessem frequentar o nível seguinte de escolarização. De acordo com Antônio (2014, p. 101-102):

Se o acesso aos estudos secundários, tanto na rede pública quanto na particular, nos primeiros decênios da Primeira República foi marcado pela alteridade da matrícula masculina em detrimento do acesso feminino, o mesmo não acontece nos anos posteriores devido à tendência de crescimento da rede estadual de ginásios e colégios secundários, quando ocorreu a ampliação da rede pública de ensino secundário no Estado de São Paulo [...].

Mas os currículos ainda eram diferenciados para os gêneros, direcionando as mulheres para as carreiras que pior remuneravam e que, de preferência, as ligassem ao trabalho doméstico, como, por exemplo, - conforme a representação então vigente - o magistério.

O poder dos padrões morais era tão forte que qualquer atividade exercida pelas mulheres poderia ser abandonada para que elas ocupassem a sua "função principal", isto é, o cuidado com os filhos e o trato com o lar. Nenhuma profissão sobrepujava em importância o cuidado com as questões domésticas, sendo assim, as mulheres poderiam abandonar tudo para se dedicar somente ao lar e à família. Esta ideologia afetava as trabalhadoras, isto porque se não exerciam a

\footnotetext{
${ }^{3}$ Podemos perceber essa construção da moral quando observamos os casamentos da época. Apesar de o ideal do casamento por amor ter vencido os antigos modelos de casamentos arranjados, esses não desapareceram totalmente. A autoridade paterna ainda era preponderante na escolha de um "bom partido" para as moças. Assim, as jovens ainda não escapavam da dominação masculina e o "casamento por amor" tornava-se mais um dos esquemas de controle. Dizia-se à época que as mulheres "viviam para o amor", mas as paixões lhes eram vetadas, dado o seu potencial pernicioso que poderia levar uma moça da elite a se enamorar por rapazes de classes menos abastadas. Em suma, o casamento nos meios burgueses nos anos 1950 ainda representava, em grande medida, um negócio.
} 
sua "função natural", essas mulheres eram, portanto, desviantes, e não mereciam receber um salário compatível com a sua profissão.

Sublinhe-se ainda que foi somente no ano de 1943 que a legislação brasileira concedeu a permissão para a mulher casada trabalhar fora de casa sem a 'autorização expressa do marido. A situação de dependência e subordinação das esposas em relação aos maridos estava reconhecida por lei desde o Código Civil de 1916. (SCOTT, 2011, p. 23).

A professora Maria de L. F. Pardo relatou que sofreu com a rigidez da divisão binária que a moral burguesa impunha. Apesar de ter iniciado a sua carreira no magistério na década de 1950 e de ter ingressado no Grupo Escolar "Alfredo Westin Junior", em Presidente Bernardes, no ano de 1960, a antiga divisão que destinava as mulheres à esfera privada e os homens à esfera pública, ainda estava presente, como fica explícito na atitude de seu marido que queria impedi-la de trabalhar: "O meu marido queria que eu ficasse em casa, mas eu bati o pé. As outras também. Embora eu não dependesse do meu ordenado, mas tinha muita gente aí que precisava trabalhar". (PARDO, 2013, grifos nossos).

O que se nota também é que o trabalho doméstico era totalmente desconsiderado, pois era tido como "não produtivo", sem valor econômico. O valor desse trabalho era social. E isso valia para todas as classes sociais, variando apenas a intensidade da influência de acordo com a necessidade de cada família.

As casas deixaram de ser espaços de produção econômica para se tornarem apenas o lar, local íntimo, de descanso, o oposto do espaço público, em uma palavra, o privado. Dessa distinção surgiu a figura da dona de casa, a pessoa encarregada de todos os cuidados com o espaço doméstico, identificada, por isso, com a esfera privada e, portanto, distante do espaço público, esfera estritamente masculina. Sendo assim, o trabalho realizado no lar era tido como uma "função feminina" e não como um trabalho.

O modelo difundiu-se a tal ponto que, mesmo que as mulheres tivessem uma ocupação econômica independente ou contribuíssem financeiramente para a organização familiar, elas eram definidas e avaliadas, acima de tudo, por sua atuação doméstica. (PINSKY, 2011, p. 498).

Dentro do espaço de ação limitado que as mulheres possuíam, era difícil estabelecer resistência aos padrões impostos. Mesmo com o reconhecimento do desquite em lei, desde 1939, este ainda não era bem visto pela sociedade, principalmente no caso das mulheres, pois demonstrava que esses indivíduos não conseguiriam cumprir com a tarefa de constituir uma família.

Especialmente as mulheres das classes médias e altas que não trabalhavam fora de casa, além de enfrentarem a reprovação social por conta da separação, tinham poucas condições econômicas de manter-se, e aos seus filhos, com dignidade e independência, sem ajuda de um marido ou dos pais. Situação muito diferente da vivenciada por mulheres das famílias menos privilegiadas que, mesmo ao casar, se mantinham, formal ou informalmente, trabalhando para contribuir financeiramente na manutenção da prole e do lar. (SCOTT, 2011, p. 22-23).

Os ditames que regiam o que era uma boa esposa continuavam, mas algumas alterações já eram verificadas. O American way of life era muito atraente para a classe média brasileira, pois além de manter os padrões já existentes, trazia um pouco de modernidade com os seus aparelhos 
(eletrodomésticos, automóveis, etc. $)^{4}$. Entretanto, para alimentar esse modo de vida consumista era necessário um incremento na renda familiar que poderia prover do trabalho feminino. Essa era uma das contradições acarretadas pela modernidade.

Deste modo, as professoras procuravam conciliar a vida doméstica com a vida profissional. Isto demandou jogar com as possibilidades que o contexto lhes apresentava, tendo em vista a tensão entre o desejo (e a necessidade) de atuar no magistério e, concomitantemente, a tentativa de manter a harmonia nas relações conjugais:

A luta das mulheres não era contra um inimigo odiado ou um sistema governamental, era contra seres próximos e amados que participavam do cotidiano e compartilhavam da existência, com suas dores e alegrias. Como, pois, identificar esses sutis e nem tão sutis mecanismos de dominação e subordinação de forma racional? Como proceder ao confronto no espaço público, se na privacidade dos lares o desejo de felicidade e harmonia era uma realidade? Essa é uma explicação perfeitamente plausível para justificar as poucas vozes femininas que insurgiram-se contra o discurso masculino e intentaram, a duras penas e com grande ônus pessoal, fazer valer seus direitos e concretizar seus desejos, assim como as que optaram permanecer em silêncio ou concordar timidamente. (ALMEIDA, 1998, p. 141).

As docentes tiveram de proceder a ajustes na rotina doméstica, às vezes abrindo mão de algumas conquistas, para poderem se manter na profissão. Entre avanços e retrocessos, as professoras iniciavam a sua vida profissional nos grupos escolares do extremo oeste paulista, tendo que enfrentar também os desafios que o trabalho no magistério lhes apresentava naquela localidade.

A partir da década de 1950, com a ideologia desenvolvimentista imperando, o país passou a se modernizar. Deste modo, os lares urbanos se encheram com todos os tipos de novidades tecnológicas em matéria de eletrodomésticos, o que aliviava o trabalho doméstico ${ }^{5}$. Com esses modernos produtos fazendo parte do cotidiano doméstico, o trabalho ganhou mais agilidade, por isso o que se preconizava era a eficiência.

Assim, em meados do século XX o otimismo gerado pelo desenvolvimento econômico do Brasil trazia novas oportunidades para as mulheres. Os setores de serviços se diversificaram e os empregos nas áreas da burocracia, do magistério, nos bancos, no comércio, nas profissões liberais, poderiam ser procurados pelas mulheres já que naquele momento elas eram mais valorizadas e o seu nível de escolaridade também era maior. (PINSKY, 2011).

\section{CONCLUSÃO}

Nos anos da década de 1950 foi possível perceber uma ampliação das perspectivas profissionais para as mulheres nos anos dourados, uma conquista alcançada principalmente pelo aumento de sua escolaridade. Apesar da força exercida pelas representações que ainda ligavam as mulheres à esfera doméstica, com a exaltação da figura da dona-de-casa, a presença feminina

\footnotetext{
${ }^{4}$ Mesmo pertencendo à classe média, alguns produtos da modernidade demoravam a chegar nas regiões mais longínquas, como era o caso do oeste paulista. A Prof. a Maura Pereira Estrela, por exemplo, relatou que ela foi uma das primeiras professoras a possuir um automóvel em Presidente Venceslau, mas já após a década de 1950: “Eu tinha uma empregada [doméstica], mas a maioria [das professoras] não tinha. Eu fui uma das primeiras que teve carro, o Manoel comprou para mim e ele tinha o carro dele. Em 1964 eu peguei a carta [de motorista]. E o Manoel comprou o carro para mim porque ele ia com a perua para a fazenda. Eu levava todo mundo, todos os meus vizinhos iam comigo. lam dez professoras lá dentro! Fomos as primeiras, eu e a Zélia Deco, porque o marido dela era fazendeiro". (ESTRELA, 2013, acréscimos nossos).

5 "E não foram só as máquinas que modificaram a repetitiva jornada de trabalho doméstico, aliviando seu fardo. A disponibilidade de produtos de limpeza industrializados poupava a dona de casa de ter que fabricá-los. Os utensílios de plástico substituíam os antigos, mais pesados e caros. Os tecidos sintéticos, mais 'leves e funcionais' que os de algodão, lã ou linho, facilitavam as tarefas de lavar e passar. Os alimentos enlatados e processados industrialmente, adquiridos no mercado, diminuíram o tempo dedicado ao preparo das refeições. As roupas prontas vendidas em lojas e magazines concorriam com vantagens com as confeccionadas em casa, ainda que na máquina de costura". (PINSKY, 2011, p. 500).
} 
cada vez maior nas escolas, seja como discente ou como docente, proporcionou um avanço significativo no sentido de sua emancipação.

Por fim, foi a educação que, em grande medida, proporcionou a ampliação das perspectivas profissionais, fazendo com que as mulheres deixassem a condição de indivíduos totalmente desprovidos de direitos, para alcançarem (mais em direito do que efetivamente) a cidadania e a possibilidade de participarem, através do voto, nos rumos que o país tomaria. Como ressalta Rachel Soihet (2011, p. 234), os opositores dessa ascensão feminina acertaram quando vaticinaram que as mulheres nunca mais seriam as mesmas.

\section{REFERÊNCIAS}

ALBERTI, Verena. Manual de História Oral. 3. ed. Rio de Janeiro: Editora FGV, 2005.

ALMEIDA, Jane Soares de. Vestígios para uma reinterpretação do magistério feminino em Portugal e Brasil. In: SOUZA, Rosa Fátima de; VALDEMARIN, Vera Teresa e ALMEIDA, Jane Soares de. 0 Legado Educacional do Século XIX. Araraquara: UNESP - Faculdade de Ciências e Letras, 1998b.

ANTÔNIO, Mara Rúbia dos Santos. A presença feminina nos estudos secundários no estado São Paulo (1930-1947). 2014. 122f. Dissertação (Mestrado em Educação). Faculdade de Ciências e Letras, Universidade Estadual Paulista, Araraquara.

ESTRELA, Maura Pereira. Maura Pereira Estrela: depoimento [mai. 2013]. Entrevistador: Jorge Luís Mazzeo Mariano. Presidente Venceslau: 2013. 1 arquivo .mp3 (3 hrs 48 min 48 seg). A entrevista encontra-se transcrita em mídia digital no arquivo pessoal do pesquisador.

FERREIRA, Marieta de Moraes; AMADO, Janaína (Coord.). Usos \& abusos da História Oral. 8. ed. Rio de Janeiro: FGV, 2006.

JOUTARD, Phelippe. Esas voces que nos llegan del pasado. México: Fondo de Cultura Econômica, 1986.

MARIANO, Jorge Luís Mazzeo. As influências do trabalho docente feminino na cultura escolar do extremo oeste paulista (1932-1960). 2016. 405f. Tese (Doutorado em Educação) - Universidade Estadual Paulista, Faculdade de Ciências e Tecnologia, Presidente Prudente.

PARDO, Maria Aparecida de Lourdes Fontana. Maria Aparecida de Lourdes Fontana Pardo: depoimento [set. 2013]. Entrevistador: Jorge Luís Mazzeo Mariano. Presidente Bernardes: 2013. 1 arquivo .mp3 (1 h 55 min $01 \mathrm{seg}$ ). A entrevista encontra-se transcrita em mídia digital no arquivo pessoal do pesquisador.

PINSKY, Carla Bazanessi. A era dos modelos rígidos. In: PINSKY, Carla Bassanezi; PEDRO, Joana Maria (Orgs.). Nova História das Mulheres. Contexto: São Paulo, 2011. p. 469-512.

SCOTT, Ana Silvia. O caleidoscópio dos arranjos familiares. In: PINSKY, Carla Bassanezi; PEDRO, Joana Maria (Orgs.). Nova História das Mulheres. Contexto: São Paulo, 2011.

SOIHET, Raquel. A conquista do espaço público. In: PINSKY, Carla Bassanezi; PEDRO, Joana Maria (Orgs.). Nova História das Mulheres. Contexto: São Paulo, 2011. 
SOUZA, Rosa Fátima de Souza; DINIZ, Carlos Alberto. A articulação entre estado e municípios na expansão do ensino secundário no estado de São Paulo (1930 - 1947). In: DALLABRIDA, Norberto; SOUZA, Rosa Fátima (orgs.). Entre o ginásio de elite e o colégio popular: estudos sobre o ensino secundário no Brasil (1931 - 1961). Uberlândia: EDUFU, 2014.

THOMPSON, Paul. A voz do passado: história oral. Trad. de Lólio Lourenço de Oliveira. Rio de Janeiro: Paz e Terra, 1992. 